\title{
BEDSIDE DIAGNOSIS OF CONGENITAL HEART DISEASE
}

\author{
By WALTER SOMERville, M.D., M.R.C.P. \\ Assistant Physician, Department of Cardiology, The Middlesex Hospital, Cardiologist, Thoracic Surgical Unit, Harefield \\ Hospital.
}

Before the last world war, there was little interest in the bedside diagnosis of congenital heart disease. A great deal of information on the anatomy had been accumulated through the centuries, and Maude Abbott's 'Atlas of Congenital Cardiac Disease,' which appeared in 1936, incorporated all the knowledge compiled up to that time. In its field, it was a remarkable and epochmaking work, but it dealt entirely with postmortem diagnosis of which it is still the standard reference text.

Three factors were mainly responsible for awakening interest in the clinical features of congenital heart disease, and all three came to light in the immediate post-war period. The most important fillip was the beginning of cardiac surgery in the United States, the operations for patent ductus arteriosus and Fallot's Tetralogy. The second stimulus was the introduction and technical improvement in cardiac catheterization and angio-cardiography. The third was the publication in 1947 of Helen B. Taussig's 'Congenital Malformations of the Heart.' Taussig underlined the value of radiology in diagnosis and correlated the findings with the anatomy; the chief merit of her work is that it embodied the separate researches of many in the inter-war years, including, in the United States, Burwell, Eppinger and White, and in this country, Brown, Parkinson, Bedford, Lewis and others. Once the theme was set, progress was made at a rapid tempo. The key which solved many clinical problems was the ease with which the blood pressure could be measured in the heart and great vessels by cardiac catheterization, and shunts of blood from arterial to venous circulations, and vice versa, could be measured and localized. By I950, much progress had been achieved with the correlation of the deranged anatomy and physiology with the clinical findings, electrocardiogram (ECG) and radiogram. This new approach to congenital heart disease was well illustrated by Wood (1950) in the St. Cyres Lecture of 1950. The bedside diagnosis of the commoner conditions with which this article is concerned is now on so firm a footing that catheterization and angiocardiography are usually unnecessary. Uncommon or complex cases, however, can only be understood by these investigations. There remain many bizarre and complicated anomalies which cause death in early infancy. These cannot be diagnosed ante-mortem and will not be referred to further.

There are six conditions which account for over 80 per cent. of all congenital heart diseases found in children and adults. Five of them are acyanotic; atrial septal defect, patent ductus arteriosus, ventricular septal defect, pure pule̊ monary stenosis and coarctation of the aorta, is order of frequency. The sixth is cyanotic Fallot's Tetralogy. In children surviving beyon at infancy, the acyanotic conditions outnumber the cyanotic by three or four to one. This, then, is the first point to establish when setting about the diagnosis of any case: is it acyanotic or cyanotic?

\section{Detection of Cyanosis}

The florid case of cyanosis can be recognized at a glance. Difficulty may occur in very young children, in children of foreign parentage and when a dusky hue of the lips suggests cyanosis but the skin is otherwise pink. Clubbed fingers are seldom a help because if clubbing is obvious, so too is cyanosis; the earliest changes of clubbing raise the same uncertainties as the suspicious tinge of cyanosis. The haemopoietic tissues are at least moderately sensitive to changes in arterial oxygen saturation, and episodal cyanosis can often be recognized from a slightly increased haemoglobin level or red cell count. The simplest method of uncovering episodal cyanosis is by comparing the colour of lips and skin before and after exercise; if the fall in arterial oxygen saturation can be measured by oximeter or arterial puncture, so much the better, but often the colour change is obvious and the question of cyanosis answered. 
Cyanotic

Right Ventricle

Pulmonary stenosis with

right-to-left shunt-usually

Fallot.

$\left[\begin{array}{l}\text { Eisenmenger's group. } \\ \text { Transposition of great } \\ \text { vessels. }\end{array}\right]$
Left Ventricle

[Tricuspid atresia.]
Right Ventricle
Atrial septal defect.

Pure pulmonary stenosis.
Acyanotic

Left Ventricle

Patent ductus arteriosus.

Ventricular septal defect.

Coarctation of aorta.

(Conditions in brackets are uncommon.)

\section{Detection of Right or Left Ventricular Enlargement}

The next step is to decide whether the right or left ventricle is enlarged. If this can be done, a further breakdown is possible along these lines.

The two bedside guides to ventricular enlargement are the cardiac impulse and the ECG.

With even a slight degree of left ventricular hypertrophy, the apex has a localised thrusting quality, best sensed by the finger-tips in the appropriate interspaces. With well-developed left ventricular hypertrophy, in rheumatic more so than congenital lesions, an additional sign is systolic retraction over the right ventricle, which often presents with the thrusting apex a striking seesaw appearance.

In right ventricular enlargement the apex has sometimes a tapping quality, particularly in children, but more often this site-by definition the downmost and outmost point at which cardiac pulsations can be felt-is not helpful. This is because the enlarged right ventricle extends to the left from the sternum, and its typical heaving or lifting impulse is therefore seen or felt in the left para-sternal region and not at the apex. This sign is most obvious in atrial septal defect, when the right ventricular stroke output is increased, and less so in pulmonary stenosis and Fallot's Tetralogy, when it is normal or reduced.

Sometimes, however, even the experienced hand can be deceived by the cardiac impulse. The ECG is the surest guide to ventricular hypertrophy and in most cases gives the answer at a glance.

\section{Cyanosis with Right Ventricular Hypertrophy}

Fallot's Tetralogy will account for most cases under this heading. The distinguishing physical signs are produced by pulmonary stenosis- systolic murmur which is usually short and ends

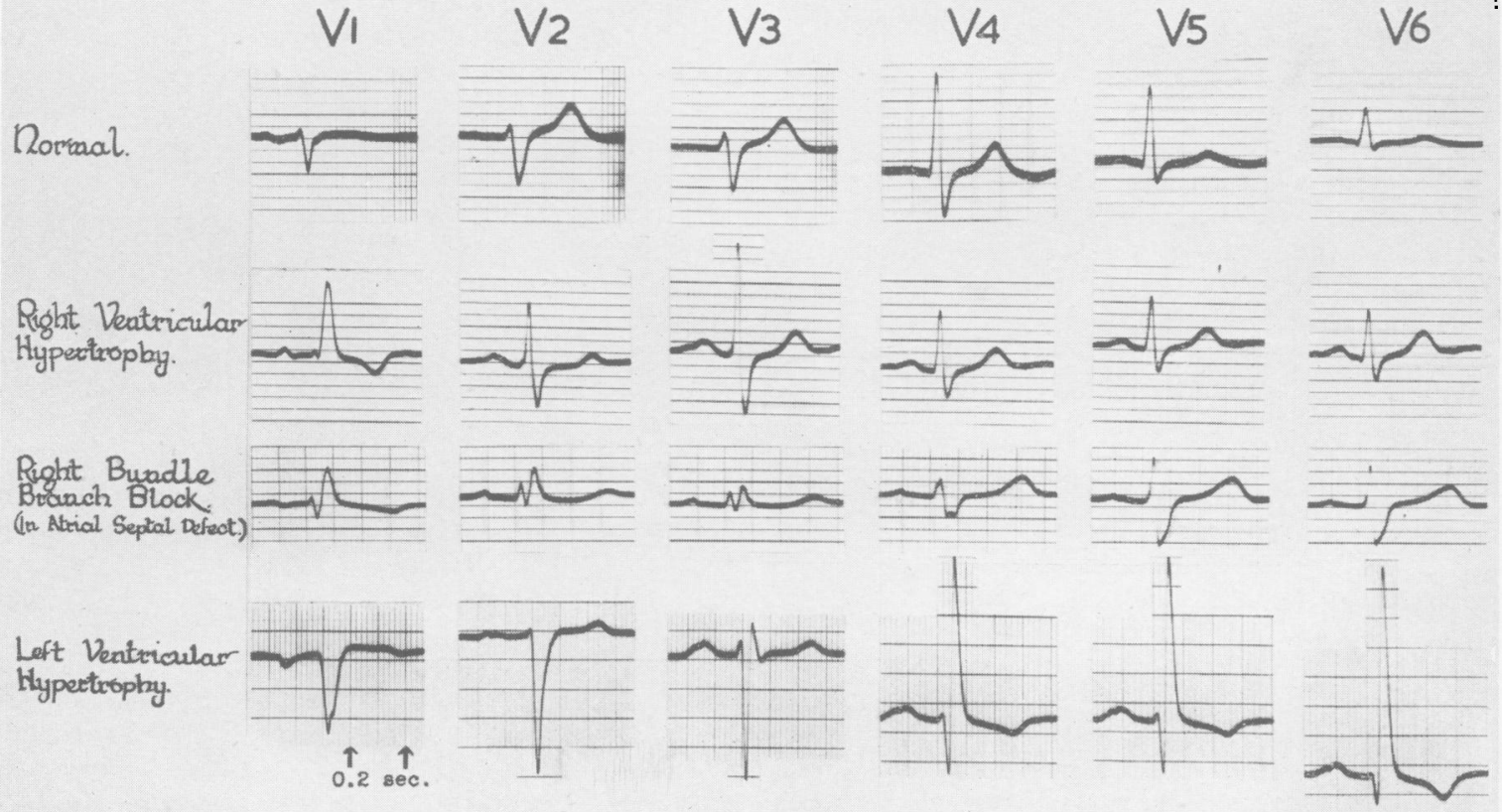

Fig. r.-Electrocardiogram (chest leads) in ventricular hypertrophy. Atrial septal defect is mentioned separately because the pattern of right bundle branch block is so characteristic of this condition that the bedside diagnosis should never be made without it. 
well before the second sound and, when the murmur is loud, a thrill. The stenosis is usually situated in the infundibulum of the right ventricle, when the thrill and murmur are maximal in the third or fourth left interspace. If they are higher, it means that the stenosis is high in the infundibulum or at the pulmonary valve. However, loud murmurs in small children are difficult or impossible to localize, and often the nurmur gives no indication of the site of the stenosis. The second heart sound may be loud and is almost invariably single, the pulmonary element $\left(\mathrm{P}_{2}\right)$ being inaudible; if distinct splitting is confirmed, it makes the diagnosis of Fallot highly improbable.*

A related but anatomically different condition is pulmonary stenosis with reversed inter-atrial shunt, sometimes called Fallot's Trilogy. The three components are pulmonary stenosis, atrial septal defect and right ventricular hypertrophy. Here, the aorta does not override the ventricular septum, and consequently there is no ventricular septal defect. While cardiac catheterization may be required for confirmation, there are five clues which may allow this condition to be distinguished from Fallot's Tetralogy at the bedside. Three of

*The norma! second heart sound has two audible components, $A_{2}$ caused by closure of the aortic valve, and $\mathrm{P}_{2}$ closure of the pulmonary valve. In expiration, $\mathrm{A}_{2}$ and $P_{2}$ are fused and the second sound is single. Inspiration separates them slightly and the sound is split. them result from the much higher pressure generated in the right ventricle in the Trilogy than Tetralogy:

(i) Prominent pre-systolic venous waves (' a' waves) are often seen in the neck; they are seldom present in the Tetralogy.

(ii) The cardiac impulse of right ventricular hypertrophy is as a rule easily felt, while in the Tetralogy, although present, it may be inconspicuous.

(iii) The greater degree of right ventricular hypertrophy may be reflected in the ECG which often shows large inverted $T$ waves in all or most of the chest leads.

The remaining two clues are:

(iv) The systolic murmur is longer than in the Tetralogy where the blood leaves the right ventricle by two routes, the stenosed outflow tract and the aorta, the ventricle thereby emptying quickly. In the Trilogy, all the right ventricular blood must leave through the stenosis, emptying time is slower and the murmer consequently longer.

(v) The X-ray appearances of Fallot's Tetralogy with infundibular stenosis are characteristic. There is usually a concavity on the left cardiac border corresponding to the pulmonary artery, in contrast to a convexity in the Trilogy

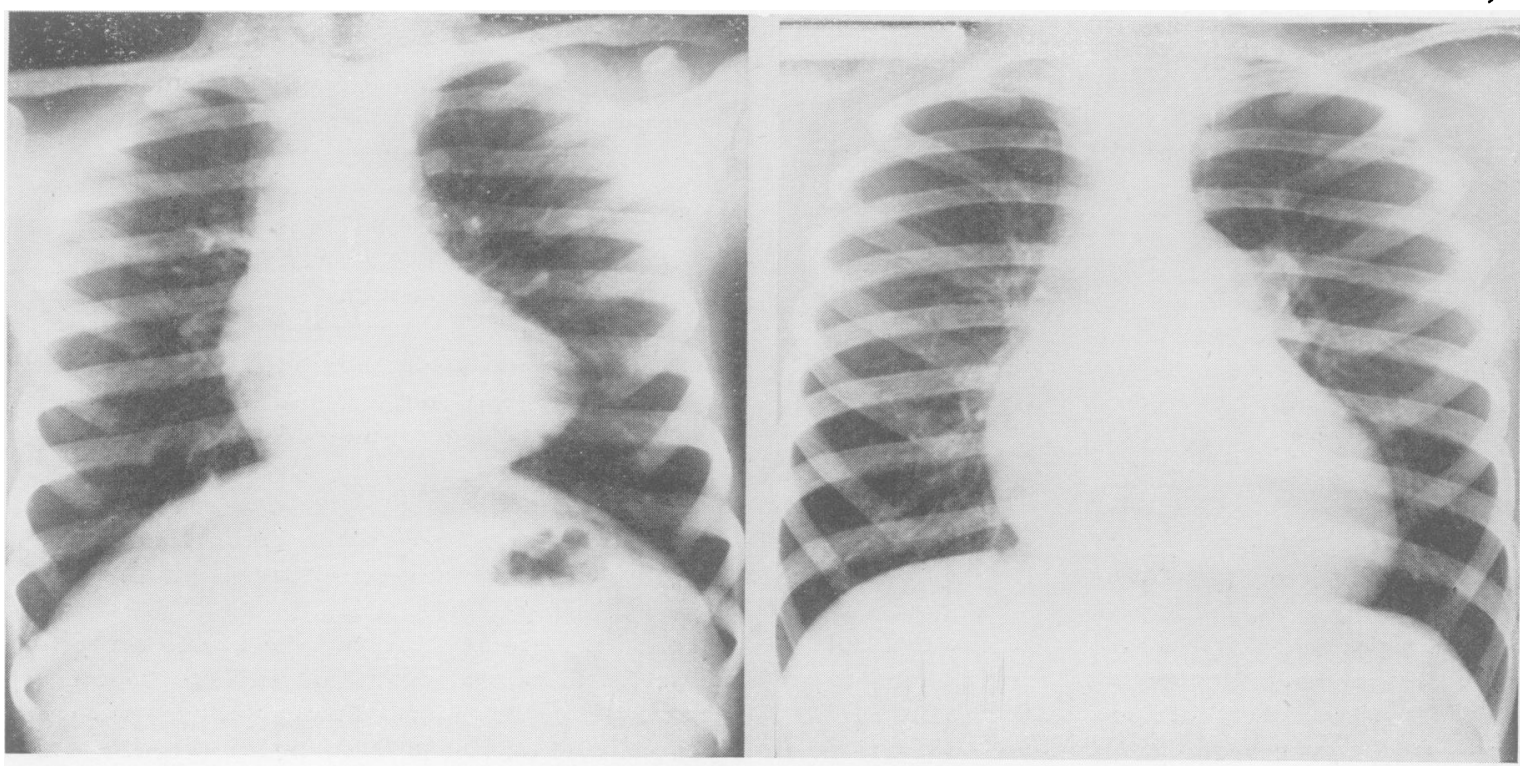

FIG. 2.-Teleradiograms of (A) Fallot's Tetralogy, proven by angiocardiography, and (B) pulmonary stenosis with reversed interatrial shunt-Fallot's Trilogy-confirmed by necropsy. 
caused by the post-stenotic dilatation of the pulmonary artery (Fig. 2).

Pulmonary atresia is an extreme form of Fallot's Tetralogy; atresia is substituted for pulmonary stenosis while the other three components remain the same. Blood reaches the lungs via bronchial arteries which cause a continuous, machinery-like murmur, well-heard on back and front of the chest, and usually on both sides. This murmur replaces the systolic murmur and thrill of the Tetralogy.

Two other conditions in this group, both uncommon, are worth mentioning; transposition of the great vessels and pulmonary hypertension with a right-to-left shunt (the Eisenmenger Group). In neither can a complete diagnosis be made by the bedside. However, many cases of transposition can be recognized by the combination of deep cyanosis with radiological pulmonary plethora. In pulmonary hypertension, there are prominent venous ' $a$ ' waves in the neck, the pulmonary artery may be palpable in the second left interspace, a pulmonary systolic murmur may be slight or absent, there is a loud pulmonary systolic click, the pulmonary element of the second sound is loud and often palpable and a Graham Steell murmur of pulmonary incompetence may be heard. Catheterization is necessary to demonstrate an associated septal defect or patent ductus arteriosus, or to prove over-riding of the aorta in the true Eisenmenger Complex.

\section{Cyanosis with Left Ventricular Hypertrophy}

Tricuspid atresia is the only lesion of clinical importance under this heading. Cyanosis and clubbing are extreme.

\section{Acyanotic Cases with Right Ventricular Hypertrophy}

\section{Atrial Septal Defect}

The main features are an easily visible and palpable right ventricle and often the pulmonary artery can be felt with the finger-tips in the second left interspace. When the shunt is large, the right ventricular pulsations are vigorous and heaving in quality. The overfilled right ventricle may be felt extending from the sternum as far out as the left anterior axillary line and in this position there may be difficulty in distinguishing it from a hypertrophied left ventricle. The ECG should be consulted to decide the point; right bundle branch block is characteristic of atrial septal defect (Fig. I) and the diagnosis should not be made without it. A systolic murmur, loudest in mid-systole, is heard over the pulmonary artery and when the shunt is large, there may be a thrill. The second sound is widely split in all phases of respiration. In one-third of the cases, a long soft pulmonary diastolic murmur is present in the third to fourth left interspaces when a greatly dilated pulmonary artery gives rise to pulmonary incompetence. A shorter delayed diastolic murmur may be heard at the apex, often with a loud and sharp first sound simulating mitral stenosis; these signs are currently believed to be the result of a greatly increased blood flow through the tricuspid valve. The $\mathrm{X}$-ray appearances are characteristic; the right atrium and ventricle and pulmonary artery are prominent and the pulmonary vascular shadows increased in number and size (Fig. 3A).

The child with an atrial septal defect may have a perfectly normal appearance. Various congenital stigmata, however, are fairly frequently seen, such as arachnodactyly, high palate, chest deformities, syndactyly, polydactyly and deformities of the external ear.

\section{Pulmonary Stenosis}

For some inexplicable reason, pulmonary stenosis as an isolated lesion was until recently a forgotten disease. In 1947 , Helen Taussig wrote in the first edition of her book 'Congenital Malformations of the Heart' that she had never seen a proven case. Yet today, the diagnosis is made routinely at the bedside. A pulmonary systolic thrill and murmur filling systole are the main features. In some cases, an early systolic click is heard over the right ventricle. Compared with atrial septal defect, the right ventricular pulsations are quieter, but more vigorous than in Fallot's Tetralogy where they may be inconspicuous. Both elements of the second sound are heard in mild cases, the pulmonary element $\left(\mathrm{P}_{2}\right)$ diminishing as the stenosis becomes more marked. In severe cases, pulmonary valve closure is inaudible and the second sound is single, $\mathrm{A}_{2}$ only being heard. Other signs of severe pulmonary stenosis are giant venous ' a ' waves in the neck, an easily palpable right ventricle and deeply inverted $\mathrm{T}$ waves in leads $\mathrm{VI}_{\mathrm{I}-4}$ of the ECG. The X-ray shows a prominent main pulmonary artery (poststenotic dilatation) with decreased pulmonary vascular shadows, depending on the severity of the stenosis (Fig. $3 \mathrm{~B}$ ).

Even in severe cases of pulmonary stenosis, symptoms may be absent or slight in contrast to the invariably diminished exercise tolerance of Fallot's Tetralogy.

Wood and others (1954) have recently described the acyanotic type of Fallot's Tetralogy. Anatomically it is identical with the commoner cyanotic type, but clinically, it may be confused with pulmonary stenosis or ventricular septal defect. Bedside recognition of this condition is not easy but the following clues should bring it to mind: there is more or less breathlessness on exercise 

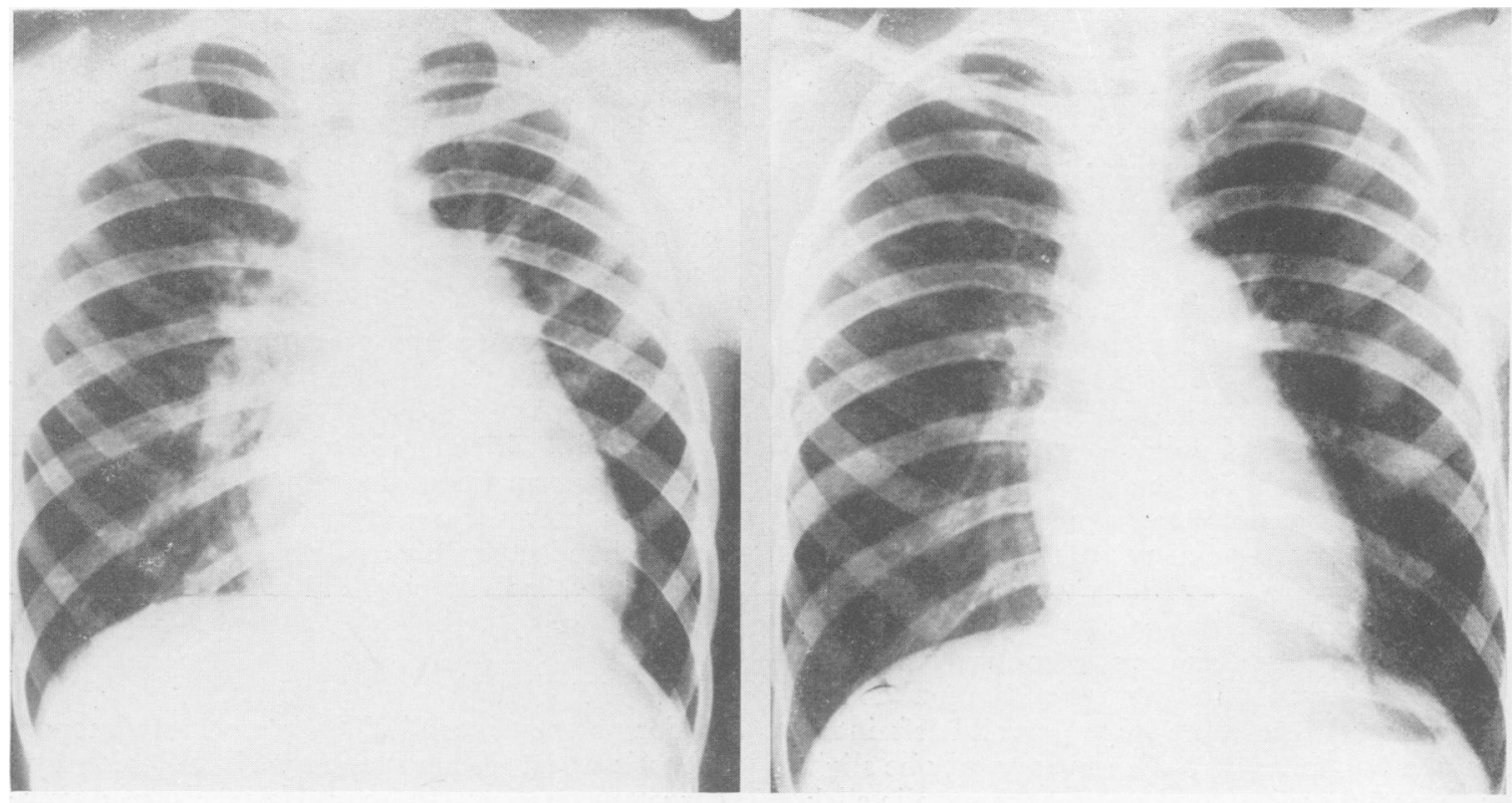

FIG. 3.-Teleradiograms of (A) atrial septal defect and (B) pure pulmonary stenosis. Both patients were girls aged i2. Diagnosis was confirmed in each case by cardiac catheterization.

(unusual in a comparable case of pulmonary stenosis); a systolic thrill and murmur in the third to fourth left interspaces are followed by a single second sound (distinguishing it from ventricular septal defect); X-ray of the heart and pulmonary blood vessels is usually normal and the ECG, as a rule, shows some degree of right ventricular hypertrophy.

\section{Acyanotic Cases with Left Ventricular Hypertrophy}

\section{Patent Ductus Arteriosus}

The continuous machinery or Gibson murmur in the pulmonary area is the tell-tale sign of patent ductus arteriosus. The diagnosis should be questioned if the murmur is loudest elsewhere, for other arterio-venous fistulae can give a similar murmur, e.g. aorto-pulmonary fistula, pulmonary arterio-venous aneurysm, ruptured aneurysm of a sinus of Valsalva and bronchial collateral circulation. When the shunt through the ductus is large, the peripheral signs of vaso-dilatation will be prominent, such as a water-hammer pulse and digital throbbing. A short mitral diastolic murmur produced by an increased blood flow through the mitral valve is a common finding. The ECG is normal or shows some degree of left ventricular hypertrophy. The pulmonary vascular shadows are increased radiologically, the pulmonary artery more or less prominent and the left ventricle enlarged (Fig. 4A).
In a small number of cases, the murmur of the patent ductus may lack the characteristic machineryo quality. The commonest cause of this atypica murmur is associated pulmonary hypertension The signs of right ventricular hypertrophy with corresponding ECG changes will then be found. Indeed the discovery of pulmonary hypertension in a young person should always indicate cardiac catheterization to search for a patent ductus, for surgical closure, if effected in time, can result in more or less reduction of the pulmonary pressure.

\section{Ventricular Septal Defect}

In the mildest cases of ventricular septal defect (Roger's disease), neither ventricle is enlarged. In moderate and severe cases both are involved but the localized hyperactive or thrusting pulsations of the left are more readily palpable. The most constant sign is a long systolic thrill and murmur extending throughout systole, enveloping the second sound and loudest at the third and fourth left interspaces close to the sternum. The second sound is usually difficult to hear through the murmur, but it can be picked up a little above, below or to one side of the loudest site of the murmur, and then both elements of the sound can be heard.

The ECG is normal in the mild cases. Otherwise, the confirmatory signs of left ventricular enlargement are seen in $\mathrm{V}_{5}-6$ ( $Q$ waves, tall $R$ waves and in the severe cases, $\mathrm{ST}$ and $\mathrm{T}$ wave 


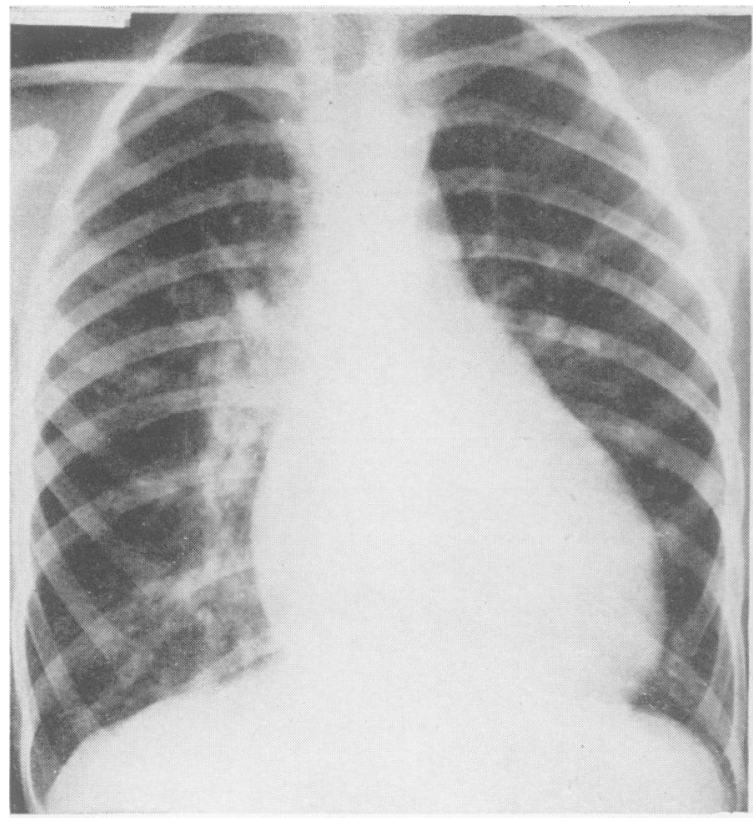

A

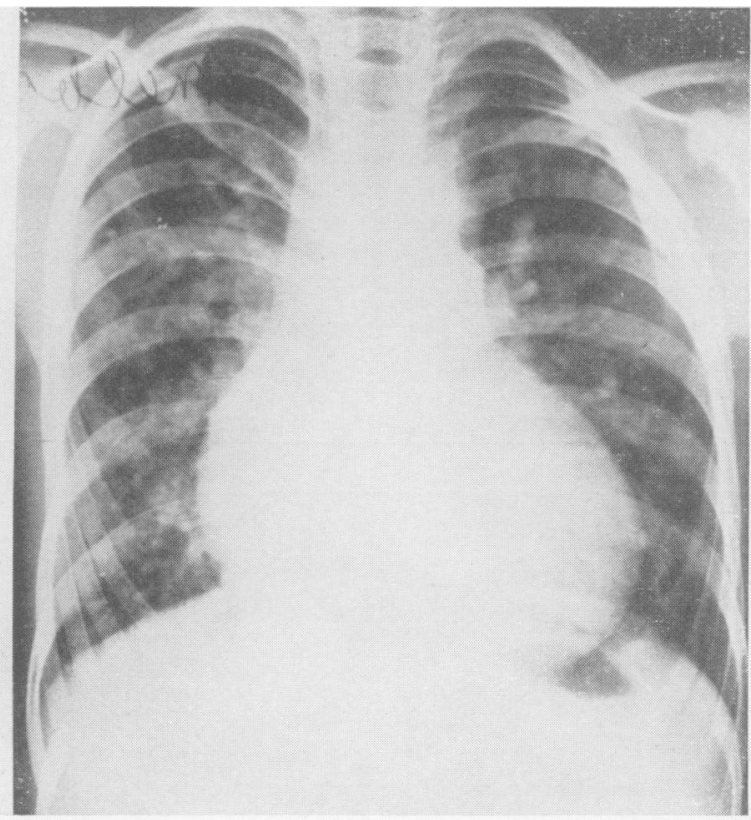

$\mathrm{B}$

Fig. 4.-Teleradiograms of (A) patent ductus arteriosus-later ligated-in a girl aged 5, and (B) ventricular septal defect, confirmed by cardiac catheterization in a girl aged 5 .

changes). Tall secondary $\mathrm{R}$ waves or incomplete right bundle branch block indicating right ventricular enlargement, are found in $\mathrm{VI}-2$. $\mathrm{X}$-ray appearances vary from normality to more or less pulmonary plethora, enlargement of left and right ventricles, and prominence of the pulmonary artery (Fig. $4 \mathrm{~B}$ ). The radiological findings are not diagnostic, being similar to those of patent ductus arteriosus, but they are valuable supporting evidence of ventricular septal defect.

The above remarks refer only to uncomplicated ventricular septal defect. Other lesions such as an aortic incompetence and pulmonary stenosis may be present at the same time and then a complete diagnosis must depend on catheter studies.

\section{Coarctation of the Aorta}

Measurement of the blood pressure is a poor diagnostic aid in congenital heart disease except in coarctation of the aorta. A rough estimate of pulse tension may be made by applying pressure to the brachial artery at the elbow with thumb or finger until the radial pulse is obliterated. With practice, the fingers can be quickly trained to recognize increased tension. The femoral pulse should then be sought, preferably with the foot in full lateral rotation which helps to uncover the artery in the groin. In coarctation, femoral pulsations are usually present but are weak and when the pulse rate is not too rapid, a delay can be appreciated between the femoral and radial pulses. Collateral vessels can usually be seen and felt on the back in children over ten years. A systolic murmur is heard over the precordium and the upper part of the back in or close to the mid-line. A short mitral diastolic murmur is common, probably caused by a slight congenital or rheumatic deformity of the mitral valve. Aortic stenosis or incompetence is sometimes present, and at necropsy, a bicuspid valve is often found to be the seat of these lesions. The ductus arteriosus is patent in ro per cent. of cases. Radiologically, the characteristic signs are rib-notching and a double aortic knuckle.

\section{Aortic and Subaortic Stenosis}

A systolic murmur, often with a thrill, is best heard in the aortic area and is transmitted to the carotids. Sometimes it begins with an early systolic click. In contrast to the murmur of mitral incompetence and ventricular septal defect, it is loudest in mid-systole and appears to end before the second sound. The aortic element of the second sound $\left(A_{2}\right)$ is normally audible over the carotids and at the apex. In rheumatic aortic stenosis in adults it is absent in all but the mildest cases. It is difficult to be sure in children with 
aortic stenosis whether the origin of the second sound is aortic, pulmonary or both, but in any event, it may be well heard even when the stenosis is undoubtedly severe. Neither is the pulse a good guide as it may be in adults, for when the rate is rapid, the interval between beats is too short to allow recognition of a distinctive pattern. The radiogram may show a rounded ventricular shadow or left ventricular hypertrophy, but more often, and especially in young children, it is of little diagnostic value.
Acknowledgments

In compiling these facts, the writer has drawn freely from the literature and from the teaching and experience of many. $\mathrm{He}$ is particularly indebted to Dr. Paul Wood who initiated him in the physical signs of congenital heart disease and to Dr. Evan Bedford, his senior colleague at the Middlesex Hospital.

\section{BIBLIOGRAPHY}

WOOD, P. (1950), Brit. med. F., ii, 639. WOOD, P., MAGIDSON, O., and WILSON, P. A. O. (1954),
Brit. Heart Ғ., 16, 387.

\section{RHEUMATIC DISORDERS}

(Postgraduate Medical Journal)

Price 3s. 10d. post free

INTRODUCTION: THE RHEUMATIC DISEASES

F. Dudley Hart, M.D., F.R.C.P.

RECENT ADVANCES IN THE PATHOLOGY OF CHRONIC ARTHRITIS AND RHEUMATIC DISORDERS

D. H. Collins, O.B.E., M.D., M.R.C.P.

\section{RHEUMATOID ARTHRITIS}

J. J. R. Duthie, F.R.C.P.E.

\section{OSTEOARTHRITIS}

G. C. Lloyd-Roberts, M.B., F.R.C.S.
GOUT

R. M. Mason, D.M., M.R.C.P.

THE RARER ARTHROPATHIES

F. Dudley Hart, M.D., F.R.C.P.

PHYSICAL METHODS IN THE TREATMENT OF RHEUMATIC DISORDERS

W. S. Tegner, F.R.C.P.

THE SURGERY OF RHEUMATIC DISEASE

JohN Bastow, M.D., F.R.C.S.

Published by

THE FELLOWSHIP OF POSTGRADUATE MEDICINE 60, Portland Place, London, W.1

Bibliography continued from page 61-F. Norman Pattinson, M.B., B.Chir., D.M.R.D., F.F.R.

CASTEllanOS, A., and PEREIRAS, R. (1939), Rer. cubana Cardiol., 2, 187.

CAS'TELlanOS, A., PEREIRAS, R., and GARCIA, O. (I950), Amer. F. Roentgenol., 64, 255.

COPE, D. H. P. (1953), Brit. F. Anaesth., 25, 212.

DOTTER, C. T., and JACKSON, F. S. (I950), Radiology, 54, 527.

DOTTER, C. 'T., and STEINBERG, I. (I95I), 'Angiocardiography. Annals of Roentgenology,' voi. 20, New York, Paul B. Hoeber, Inc.

DOTTER, C. T., WETCHLER, M. S., and STEINBERG, I. (1953), Radiology, 60, 691.

EMANUEL, R. W., and PAT'TINSON, J. N. (1955), Brit. Heart $\mathcal{F}$., in press.

JANKER, R. (1950), Fortschr. Rontgenstr., 72, 513.

JANKER, R., and HALLERBACH, H. (1951), Ibid., 75, 393.

JONSSON, G., BRODEN, B., and KARNELL, J. (1949), Acta radiol., Stockh., 32, 486

JONSSON, G. (1951 I), F. fac. Radiol., Lond., 3, 125.
JONSSON, G., BRODEN, B., and KARNELL, J. (r95 Ib), Acta radiol., Stockh., Suppl., 89.

JONSSON, G., BRODEN, B., and KARNELL, J. (1953), Ibid., 40, 547 .

LIND, J., and WEGELIUS, C. (1949), $\mathcal{F}$. fac. Radiol., Lond., I, 87.

LIND, J., and WEGELIUS, C. (1953a), Circulation, 7, 819.

NUVOLI, I. (1936), Policlinico, 43, 227.

SNELLEN, H. A., and ALBERS, F. H. (1952), Circulation, 6, Sor.

STEINER, R. E., and GOODWIN, J. F. (1954), F. fac. Radiol., Lond., 5 , 167.

SUTTON, D. (I955), F. fac. Radiol., Lond., in press.

WEGELIUS, C., and LIND, J. (r953b), Acta radiol., Stockh., 39, 177 .

WICKBOM, I. (1952), Ibid., 38, 343, 350. ZINSSER, H. F., and JOHNSON, J. (1953), Ann. int. Med., 39, 